\title{
Distribution and Use of Image-evoking Language Constructions in Written News
}

\author{
Ebbe Grunwald \& JøRgen Lauridsen
}

\begin{abstract}
Linguistic exposures are image constructions and some of the most distinctive mechanisms in the discourse community of journalism.

By exposing the journalistic writers add focus, detail and substantiation to their stories. Linguistic exposures are tools that evoke images in the readers' minds and help establish and improve the basis of interest and understanding.

We are combining linguistic and statistical methods to investigate exposures in the news of five Danish national papers in order to determine how widespread it is, and with what force and impact the techniques are used.

Our study contributes to existing knowledge by focusing on form rather than content. We investigate the creative use of specific structural elements of the language as the prevailing contact establishing tools of journalistic discourse. Our data are based on news from Berlingske Tidende, B.T., Politiken, Ekstra Bladet and Morgenavisen Jyllands-Posten.
\end{abstract}

Key Words: journalism, newspapers, written news, narrative tools, image constructions, metaphor

\section{Introduction}

Within recent years, several Danish and European newspaper companies have developed into media houses that integrate technologies and strategies that were formerly thought of as separate within journalism and communication. ${ }^{1}$ Furthermore, journalists are now being educated to act within cross-media environments and to handle newspaper journalism on the same professional level as radio, television and especially web journalism. Multimedia competences are consequently going to be an integrated qualification among many modern journalists. Parallel to these structural changes in work, production and educational processes, circulation figures for daily papers continue to drop. ${ }^{2}$

As a defensive strategy, newspaper companies have tried to find new ways to approach financial, organizational and mediation problems. Some of these problems have been solved by competition, mergers and rationalization. At the same time, norms and standards for the form of written news in daily papers have been allowed to shift: various subject areas have been given different editorial priorities, and new sections, supplements and newspaper designs have been developed and tested.

Parallel to these relatively rapid changes in the newspaper medium itself, new writing and narrative forms have appeared. The known genres, e.g. news journalism, con- 
structed within the frames of the 'inverted pyramid' now often appear as hybrid forms. This means that personal styles of expression more frequently find their way into newspaper articles where they challenge the anonymous writing style of traditional journalism.

At the linguistic and narrative levels of journalistic performance, these changes are hardly reflected in contemporary media theory. They are integrated into a continuous development that has taken place especially since 2000 in the form of media convergence at the economic, legal, organizational, technological, editorial and perhaps architectonical levels [Garrison, Bruce and Michel Dupagne (2003):6 ff.]. At other lower levels, e.g. those of communication platforms, genres, expression and investigation forms, the changes seem to develop as media divergence. Accordingly, many new devices have appeared as vehicles for reception of media messages, and new ways of distributing printed - and to some extent free - news have been developed. Future perspectives on this double development seem to be huge multiple platforms situated in media houses and covering all the present and earlier functions of daily papers, radio, and television [Petersen, Anja Bechmann (2006):15].

\section{The Active Narrator and the Exposures}

The following analysis focuses on the development of the linguistic and narrative craft of written journalism, especially the news. The thesis is that, today, the personal narrative style is used strategically by some of the big, national morning papers as an extension of their efforts to retain readers. The personal ways of framing and telling news are being applied in the papers to different extents in order to hold on to the remains of their shrinking readership.

In this way, the broadsheet-papers follow in the footsteps of the tabloids. Instead of merely announcing, quoting or referring to sources, the choice of a personal narrator allows the writer to use language that is based on everyday experiences and well suited to evoking images in the reader's mind. The actual phrasings may vary, but they will be referred to as a whole as linguistic exposures. Using exposures is not merely an external style of journalism, it is also a linguistic method developed consciously to help readers understand complex matters in the sometimes difficult messages from the sources.

The concept of exposure is known from photo technology, where the details of a photo are decided among other things by the focus and light chosen by the photographer. In a journalistic article, linguistic exposures are defined as formulation mechanisms used by the writer to present the details of a story in a clear and understandable way. The concept covers the methods of formulation, the purpose of which is to change abstract knowledge by means of concrete linguistic meanings [Grunwald, Smistrup et al., 1992:53 f.]. The concept specifies the writing methods behind the important principle that is widespread among professionals and known from the international technical literature of journalistic writing as the principle of don't tell it, show it! It is our claim that, in order to realize this principle as a journalistic writer, you must choose the role of an active and source independent narrator.

A writer exposes the abstract by using concrete words that have high recognition value, and that thereby evoke images in the reader's consciousness. In that sense, exposure forms a considerable part of the basis needed for the reader to understand the content of an article: 
An example: Instead of (abstractly) writing that

(1) the credit-worthiness of the country has deteriorated

the writer, when playing the role of active narrator, may choose words that focus on a number of image-evoking content qualities and, e.g., write

(2) the faces of our creditors look more and more disbelieving ${ }^{3}$

The rewriting does not represent a higher degree of truth. In fact, the image that it evokes looks more like fiction. The personalized image is the narrator's invention, but it exposes the aspect of the conception 'credit-worthiness', which has to do with 'a trusting interchange of values between parties'. The relation between the exposed expression (2) and the non-exposed (1) cannot be regarded as synonymy. It is rather a paraphrasing relation, which means that (2) shows the contents of (1), but with other words and at a more concrete, image-evoking and visual level. In the paraphrase, you understand the point via an image of a person who is expressing a loss of confidence.

The content of the word 'credit-worthiness' reflects a relation between two parties. In the exposure, this relation stands out while being described. When an effect ['a disbelieving facial expression'] represents a cause ['lack of confidence'], we will classify it as figurative and metonymic [Gibbs, 1993:258 ff.].

\section{Operational Definition}

In the present analysis, the concept 'exposure' will be used as a basis for finding mechanisms in the material investigated through which the journalist, as a writer, creates images while presenting his/her story. When they have been found and their extent and distribution estimated, part of the exposures will be analysed qualitatively.

On an operational level, exposures are linguistic expressions that

1. are descriptive, concrete and recognizable

2. use verbs, nouns or adjectives to make descriptions

3. comprise metaphorical expressions (both simple and complex expressions)

4. comprise metonymic (and synecdoche) expressions

5. comprise descriptive clichés or idioms.

It is supposed that exposures have a central function in journalistic communication because they activate the reader and increase text comprehensibility. In this way, exposures in journalistic articles show that the journalist, as a writer, makes an effort to make the meanings of the message recognizable. When journalistic writers expose, it is basically done without disregarding the global demand that a journalistic presentation of factual information always must be true.

\section{Problem Formulation}

The focus is on articles and typographically defined sections of articles (paragraphs) in which exposing language is found. The background consists of the following questions: 
- How widespread is the use of exposures in the journalism of the national Danish newspapers?

- Are there differences between the selected newspapers' use of exposures?

- Which exposure techniques are used?

- To which communication acts can the exposures be attached?

- In which topic areas - and in which newspaper sections - are exposures most commonly found?

- What consequences does the use of exposures have for the content and the communication?

The answers to these questions will be found through statistical analyses of data and qualitative analyses of text examples, which are in the statistical fields of significance. Furthermore, the thesis about the narrative in news journalism will be discussed in light of the linguistic characteristics found in the material.

\section{Material and Method}

The material for the analysis consists of one week's news journalism published in the following five Danish national papers: Berlingske Tidende, Politiken, Morgenavisen Jyllands-Posten, B.T. and Ekstra Bladet. The analysis period is Monday 6 August to 12 August 2001, which was an average week free from decisive political events that would influence the use of genres and the traditional way of writing in the newspapers.

A total of 3,991 article units were published during the week in question. Forty-five per cent of them $(1,781)$ are regular news units i.e. they do not fall into one of the categories: report, profile or interview. Commentaries, advance reports, reviews, analyses, background articles, updates on current matters and features were also not included. The main part of the news material (67.2 per cent) is classified as short notes, the rest (32.8 per cent) as longer articles with a so-called by-line, which identifies the writer by name.

The result of the selection of units from the investigation period represents a daily flow of articles based on statements or new, factual information about events, which are actual, important or sensational, from one or a few sources.

The analysis procedure for every single unit can be outlined as follows:

A news article is regarded as a sequence of text. The most basic text level can be defined as sentences. Each sentence sequence is closed by a major punctuation mark (often full stop or colon). At this level, grammatical structure and various cohesive mechanisms (e.g., adverbs used cohesively, correlative pronouns, the use of determiners and varied repetition) ensure the cohesion of the texts.

At a higher level is found the content-determined (qualitative) level of the sections, which are grouped thematically (as a section with news, sections with background, sections with essential documentation and supplementary documentation). At the level between periods and sections are the paragraphs, which are marked typographically by indents, and which are sequences that consist of one or more sentences. The analysis of article units thus operates with three sequence types: 
- Sentences (defined grammatically).

- Paragraphs (defined graphically).

- Sections (defined thematically).

The typographically marked paragraphs in the article are analysed in the study as rows of sequences, each of which performs a particular communication act. ${ }^{4} \mathrm{~A}$ communication act is determined partly lexically by the verbal meaning of the passage and partly functionally by determining the task that the verbal meaning performs in the context of the article.

A precondition for analysing paragraphs as communication acts is that article units are conceived as narrated stories: They differ from real stories in that the elements of the story are arranged and communicated.

Consequently, a source does not express him- or herself directly in an article. The source is quoted by the writer. It is also not the source who appears in the article, but the writer who refers to the source by name. Accordingly, the verbs to refer and to quote represent communication acts in this context. Observations or sensory perceptions experienced by the journalist while doing his or her research do not appear directly either. They are described or presented.

From this point of view, news articles are based on communication acts that are found in a specific order. The analysis will proceed then to examine with which communication acts the linguistic exposures occur.

The present data were collected by coding the communication acts in every single news article on the basis of the category definitions. The material was collected, read through, analysed and coded concurrently with its publication. Three coders carried out data collection and the quantitative registration by selecting and reading the articles and entering the code figures for individual article units directly into an SPSS data file. Matters of dispute concerning categorization were continually discussed. Thus, the study is based on controlled reading and interpretation of linguistic signs and structures. The coders were checked continuously to ensure that they used categories and definitions consistently - in order to ensure the highest possible coder reliability.

\section{Quantitative Analysis of Data}

In the following section, the results that emerged will be discussed using a statistical analysis model on data from registration of the structural qualities of the material. The results give a number of hints as to which cases in the material contain exposures and therefore are narrator active.

\section{Statistics: The Logistic Regression Model}

Exposures have been defined and demonstrated in the above as being linguistic expressions of first-hand experience, which are likely to be recognized by the recipient.

The analysis is expected to give a general idea of where in the material exposures are found. These findings characterize variations in the journalistic narrator activity, because exposures are the result of the journalist's choices, which are based on a number of characteristics, namely: 
- Characteristics of the paragraph: The length (column lines) of the paragraph and the type of communication act presented by the paragraph.

- Characteristics of the article in which the paragraph is included: Is the article a note or is there a by-line?

- Characteristics of the unit in which the article is included: What newspaper, what section of the newspaper, what page number?

Journalism is a creative and complex process. Variations in characteristics do not automatically strengthen or weaken the journalist's use of exposures. But it is a working hypothesis that the variation may result in an increased or reduced inclination to choose linguistic exposures. In other words: It is probable that exposures can be found in a typographical unit while the mentioned characteristics vary.

In the following, a logistic regression model is used to quantify the effect of the characteristics on the probability that exposures occur in a newspaper article. The logistic regression model can express the occurrence of exposures in terms of probability. Based on the data from the study, the model will show how a paragraph is identified by its characteristics. If the paragraph and thus the article contain an exposure, it can be seen from its characteristics.

We assume the effect of characteristics on paragraphs to be different in notes and articles, where the writer's or the writers' name(s) are stated explicitly in a by-line. Therefore, the model includes a common effect for these characteristics and an additional or interaction effect for articles that are notes.

The working hypotheses, which the model will test, can be summarized as follows:

\section{Working Hypotheses}

H1: It is more likely to find exposures in articles with a by-line from Politiken and Ekstra Bladet than in articles with a by-line from Berlingske Tidende, B.T. or Jyllands-Posten.

$\mathrm{H} 2$ : There is a difference between these newspapers concerning the probability of finding exposures in notes.

H3: Exposures are more likely to occur in articles with a by-line that make use of the communication acts describe, recount, summarize or characterize.

H4: Exposures are less likely to occur in articles with a by-line that make use of the communication acts inform, give an account of, quote or refer to.

H5: The effects mentioned in $\mathrm{H} 3$ and $\mathrm{H} 4$ are absent in notes.

H6: There are differences from one newspaper section to another regarding the probability of finding exposures in articles with a by-line.

H7: The effect mentioned in H6 is not found in notes.

H8: The longer the article, the greater the probability of finding exposures. This applies to both articles with a by-line and notes.

H9: The higher the page number, the greater the probability of finding exposures. This applies to both articles with a by-line and notes. 


\section{Presentation of Results}

The calculations, which were made using the logistic regression model, show the probability of finding exposures in articles. The results are seen from Figure 1 below. The figure examines how a number of circumstances that are mainly external to the text affect the probability of finding exposures in the articles studied.

On the horizontal axis the figure shows how the probability of finding linguistic exposures in an article is affected. The longer to the right along the vertical zero line, the greater the probability of finding exposures.

Figure 1. The Effect of Article Characteristics on the Probability of Exposure

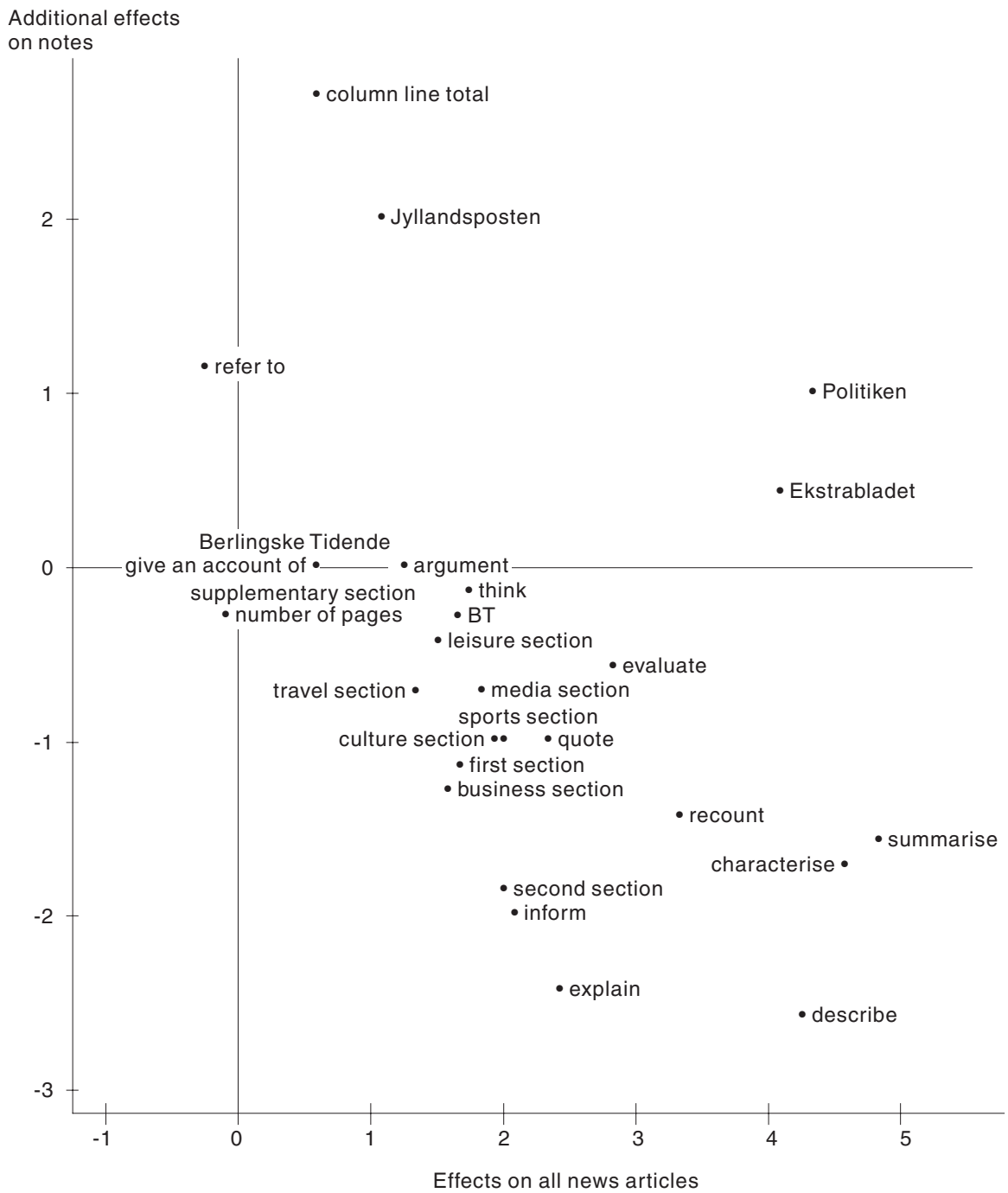

Note: The horizontal axis shows the effects of the characteristics on all news articles. The vertical axis shows additional effects on notes. The effects are centred from Berlingske Tidende, referring and supplementary section, which have all been assigned the value ' 0 ' (zero). 
On the vertical axis the figure shows positive or negative added values for articles written as notes. In the top right quadrant of the figure, the added values are positive for the annotation communicated news; in the bottom right quadrant, the added values are negative. The reason is that particular characteristics affect the probability of finding exposures in notes. The bottom right quadrant shows characteristics that influence the probability negatively, e.g. some of the communication acts, particularly inform, explain and describe. Thus, for these characteristics, the positive effect on the probability of exposure is partly or fully eliminated when notes are considered. The top right quadrant shows characteristics that influence the probability positively. Apparently this applies to some of the newspapers (Jyllands-Posten, Politiken and Ekstra Bladet) and the size of the notes in column lines. Thus, for these characteristics, the positive effect on the probability of exposure is further increased for notes.

The values assigned to the axes in Figure 1 indicate the extent to which the characteristics affect the probability that exposures will occur. A value higher than +2 (or lower than -2) means that the characteristic in question increases (or decreases) the probability of finding exposures considerably.

\section{Summary of Results}

Figure 1 is a convenient device for evaluation of the extent to which the working Hypotheses $\mathrm{H} 1$ to $\mathrm{H} 9$ are supported by the data. The following conclusions can be drawn:

- There are significantly higher probabilities of finding exposures in articles from Politiken and Ekstra Bladet than in articles from Berlingske Tidende, B.T. or Jyllands-Posten. Within the latter group, the level of probability does not differ significantly. Thus, Hypothesis $\mathrm{H} 1$ is supported by the data.

- There are differences between the notes in Jyllands-Posten and Berlingske Tidende, as the probability of finding exposures in Jyllands-Posten's notes is significantly higher than in Berlingske Tidende, but there is no difference between the articles with a by-line in the two papers. Further, we are more likely to find exposures in Politiken's notes than in B.T.'s. Thus, Hypothesis H2 is supported.

- Exposures are more likely to occur in articles with a by-line that make use of the communicative acts describe, recount, summarize or characterize. Thus, Hypothesis H3 is supported.

- Exposures are less likely to occur in articles with a by-line that make use of the communicative acts give an account of and refer to, but more likely to occur for the communicative acts inform and quote. Thus, while the former two support Hypothesis H4, the latter two do not.

- The effects reported for communicative acts are outperformed by negative additional effects for notes. Thus, the total effect of communicative acts on notes is zero, and Hypothesis H5 is supported.

- For articles with a by-line, there is a greater probability of finding exposures in the second section, the business section, the first section, the culture section and the sports section than in the travel section and the supplementary section. This supports Hypothesis H6.

- These effects of paper sections are outperformed by negative additional effects for notes. Thus, Hypothesis H7 is supported. 
- If a note is abbreviated, the probability of finding exposures decreases. If it is made longer, the probability increases. However, this effect is not found in articles with a by-line. Thus, while Hypothesis H8 is supported for notes, it is not supported for articles with a by-line.

- Page number does not have a considerable effect. Thus, the probability of encountering narrator-active forms (and exposures) does not increase with the page number, which means that Hypothesis H9 is not supported.

\section{Qualitative Analysis of Cases}

The qualitative analysis examines a limited number of articles taken from the material at hand.

By determining the average probability for exposures (ape) for an individual article, it is possible to rank all 1,781 article units. Table 2 (p. 102) gives an overview of the first 50 articles in this ranking.

\section{The Basis for the Choice of Cases}

Three hundred and thirty-four (= 19 per cent) of the article units come from Politiken and 195 (= 11 per cent) are from Ekstra Bladet. These two newspapers, which together contain 30 per cent of the material in the study, used the most narrator-active communication methods during the study period. Ekstra Bladet had the smallest number of articles and the most exposures, which indicates that this communicative form is the most preferred in this particular newspaper. Sixty-one per cent of Ekstra Bladet's news articles use at least one exposure. The share of news articles in Ekstra Bladet in which exposures are found is thus almost twice that of Berlingske Tidende with a mere 32.6 per cent.

A ranking of the newspapers with regard to number and percentage of articles, in which exposures are found, is seen in Table 1:

Table 1. Ranking of Newspapers According to Number and Percentage of Articles with at Least one Exposure

\begin{tabular}{lrc} 
Newspaper & Total & $\%$ \\
\hline Berlingske Tidende & 423 & 32.6 \\
Morgenavisen Jyllands-Posten & 479 & 35.6 \\
B.T. & 350 & 40.9 \\
Politiken & 334 & 51.5 \\
Ekstra Bladet & 195 & 61.0 \\
Total & 1,781 & \\
\hline
\end{tabular}

Total $=$ Number of news articles in the individual newspaper.

Per cent $=$ Percentage of news articles in each paper with at least one exposure.

In choosing cases for further examination, the 50 articles are used that on average show the highest predicted probabilities of exposure. The articles within this systematically defined group are all expected to be among the most narrator active and therefore most likely to provide insight into the exposure techniques used in news journalism.

Furthermore, the ranking of the material provides a basis for evaluating the method. Articles topping the list contain more exposures. Articles at the bottom of the list con- 
tain fewer or none. A qualitative analysis of specific cases must confirm and elaborate on these varying probabilities.

Table 2 gives an overview of the top 50 in the statistical ranking. In addition to ape value (= the average probability for exposure) the table provides information on: observation number, case number, the name of the newspaper, date, special section type and page number.

Table 2. The Top 50 Cases

\begin{tabular}{|c|c|c|c|c|c|c|c|}
\hline Obs & Case & Paper & Date & Sec & Page & Caption & ape \\
\hline 1 & 76 & pol & 6 & 1 & 7 & Intifada increases in strength after new assassination & 32.5 \\
\hline 2 & 998 & $\mathrm{eb}$ & 10 & $\mathrm{sp}$ & 2 & I am so happy & 32.4 \\
\hline 3 & 46 & $\mathrm{eb}$ & 6 & 1 & 16 & Feisty hostess & 31.9 \\
\hline 4 & 316 & pol & 7 & 1 & 7 & Hush, Chirac needs peace & 30.4 \\
\hline 5 & 936 & pol & 9 & net & 1 & Families with children have faster web access & 30.2 \\
\hline 6 & 1481 & $\mathrm{eb}$ & 9 & $\mathrm{sp}$ & 9 & AGF & 28.6 \\
\hline 7 & 1604 & pol & 12 & L\&S & 2 & Stop ageing & 28.3 \\
\hline 8 & 1624 & pol & 12 & 1 & 3 & Dirty gazelles in the Bella Centre & 27.9 \\
\hline 9 & 51 & $\mathrm{eb}$ & 6 & $\mathrm{sp}$ & 12 & Lazio players in press war & 27.5 \\
\hline 10 & 988 & $\mathrm{eb}$ & 10 & 1 & 8 & Acquitted of stealing & 27.3 \\
\hline 11 & 89 & pol & 6 & 1 & 9 & Rebellion against nature preservation & 27.2 \\
\hline 12 & 1023 & jp & 10 & 1 & 2 & Young man killed in front of truck & 26.9 \\
\hline 13 & 1474 & eb & 11 & $\mathrm{sp}$ & 8 & True goes Finn & 26.8 \\
\hline 14 & 778 & bt & 9 & 1 & 3 & Margrethe enjoys vacation & 26.6 \\
\hline 15 & 53 & eb & 6 & $s p$ & 18 & Iben drives the men out & 26.4 \\
\hline 16 & 542 & eb & 8 & $\mathrm{sp}$ & 2 & Tyson sex case falling apart & 26.3 \\
\hline 17 & 999 & eb & 10 & $s p$ & 8 & It's showtime & 26.2 \\
\hline 18 & 377 & eb & 7 & $s p$ & 3 & Anja reinforces & 26.1 \\
\hline 19 & 450 & bt & 7 & $s p$ & 12 & Waiting for Schmeichel & 25.9 \\
\hline 20 & 376 & $\mathrm{eb}$ & 7 & $s p$ & 2 & Green gold & 25.9 \\
\hline 21 & 61 & pol & 6 & 1 & 1 & World famous in scorpio bath & 25.8 \\
\hline 22 & 872 & $\mathrm{eb}$ & 9 & $\mathrm{sp}$ & 13 & Alex Manniger & 25.7 \\
\hline 23 & 657 & pol & 8 & kul & 2 & The most overrated & 25.6 \\
\hline 24 & 1455 & pol & 11 & 1 & 14 & pay-per-view boxing & 25.5 \\
\hline 25 & 989 & $\mathrm{eb}$ & 10 & 1 & 9 & Checks all doors & 25.3 \\
\hline 26 & 1429 & pol & 11 & 1 & 2 & Dane incarcerated for selling his child & 25.3 \\
\hline 27 & 996 & $\mathrm{eb}$ & 10 & 1 & 18 & Murder charged escaped from Danish fraud charge & 25.3 \\
\hline 28 & 47 & $\mathrm{eb}$ & 6 & 1 & 16 & Liz Taylor wants to remarry & 25.2 \\
\hline 29 & 940 & pol & 9 & net & 1 & Coffee maker for sale & 25.1 \\
\hline 30 & 357 & $\mathrm{eb}$ & 7 & 1 & 4 & Escape from mum's cooking & 25.1 \\
\hline 31 & 990 & $\mathrm{eb}$ & 10 & 1 & 10 & Tied to chair by gunmen & 25.0 \\
\hline 32 & 75 & pol & 6 & 1 & 6 & Cold reception by Greenpeace & 25.0 \\
\hline 33 & 52 & $\mathrm{eb}$ & 6 & $\mathrm{sp}$ & 16 & Threatening to boycott & 25.0 \\
\hline 34 & 1707 & jp & 12 & 1 & 7 & Charitably well-dressed & 24.9 \\
\hline 35 & 992 & $\mathrm{eb}$ & 10 & 1 & 15 & School bomb threat & 24.5 \\
\hline 36 & 95 & pol & 6 & kul & 3 & Drama on the net & 24.5 \\
\hline 37 & 1650 & $\mathrm{eb}$ & 12 & bil & 3 & Luxury MPV & 24.5 \\
\hline 38 & 37 & eb & 6 & 1 & 4 & 73 year-old kicked robber's butt & 24.3 \\
\hline 39 & 987 & $\mathrm{eb}$ & 10 & 1 & 7 & Politicians offered fortune & 24.2 \\
\hline 40 & 530 & $\mathrm{eb}$ & 8 & 1 & 5 & Forced to relive sex nightmare & 24.0 \\
\hline 41 & 48 & $\mathrm{eb}$ & 6 & 1 & 19 & 101 year-old queen & 23.9 \\
\hline 42 & 90 & pol & 6 & 1 & 9 & Plane skit out like shopping cart & 23.9 \\
\hline 43 & 941 & pol & 9 & net & 1 & Kool Keld & 23.7 \\
\hline 44 & 490 & jp & 7 & 2 & 4 & Demand for amnesty & 23.4 \\
\hline 45 & 1000 & eb & 10 & $\mathrm{sp}$ & 11 & Mikkel Lindorf & 23.4 \\
\hline 46 & 1486 & $\mathrm{eb}$ & 11 & 1 & 19 & Nanna plays with death & 23.4 \\
\hline 47 & 1651 & $\mathrm{eb}$ & 12 & bil & 12 & Pensioner goes back to work & 23.3 \\
\hline 48 & 49 & $\mathrm{eb}$ & 6 & $s p$ & 2 & Brixtofte to devour $A B$ and Lyngby & 23.3 \\
\hline 49 & 50 & eb & 6 & $s p$ & 3 & Convicted on unreliable EPO test & 23.3 \\
\hline 50 & 878 & $\mathrm{eb}$ & 9 & $s p$ & 15 & Ehlers without salary & 23.1 \\
\hline
\end{tabular}

Note $:$ Obs $=$ Observation number. Sec $=$ Special section. ape $=$ Average probability of exposure 
The figures in Table 2 confirm once again (cf. p. 101) that news journalism in Ekstra Bladet and Politiken is probably the most narrator active in Danish national newspapers: Among the top 50 we find: 15 articles from Politiken, 30 from Ekstra Bladet and 5 articles from the remaining newspapers (JP, B.T., but not Berlingske Tidende which does not make the top 50).

The high narrator activity is reflected in captions that are mainly attitude influenced, concrete, recognizable, and in several places include figurative formulations.

\section{Qualitative Problem Formulation}

The analysis of the chosen articles is based on reading, observation and interpretation of observations. It will show how and with what effect the image forming structure of the language takes place. The texts are explored in order to answer the following questions:

- Which parts of the told story are exposed?

- How does the exposure take place, i.e. which exposing figurative expressions are used?

- Which linguistic mechanisms are used in the exposures, i.e. through which mechanisms does the text become meaningful?

- How do the exposures function, what cognitive effect may we assume that they have?

\section{Working Hypotheses}

Three hypotheses have to be tested and elaborated during the qualitative analysis:

H1: Articles topping the total ranking list contain more exposures. Articles at the bottom of the list contain fewer or none.

$\mathrm{H} 2$ : Exposures amplify and visualize the focus of the article on person, time, place, (parts of) events and statements.

H3: Exposures may amplify the attitudes of the narrator with a possibility of a positive/ negative effect on the reliability of the writer.

\section{Results}

Content themes treated with exposures in the selected articles can be summed up in the following items:

1. Physical violence ('Intifada increases in strength after new assassination', Pol. 6.8.01)

2. Personal characteristics ('Trine Gregorius: Feisty hostess', EB 6.8.01)

3. Political power struggle ('Rebellion against nature preservation', Pol. 6.8.01)

4. The narrator's commitment on the story:

a. Scandal ('Politicians offered fortune', EB 10.8.01)

b. Sympathy ('Forced to relive sex nightmare', EB 8.8.01) 


\section{Re 1.}

Physical violence: The exposures use metonymic (cause-effect) or synecdochal (partwhole) mechanisms. Here the physical violence in the article is exposed by means of verbs or verb-derived forms: 'Fire(ing)', 'attack(ing),', 'kill(ing)' and 'fight(ing)'. Human beings 'are hit', 'are fabricating a suicide bomb' or are 'defending themselves', shots 'are being fired'. Descriptive verbs are found in noun forms: 'assassination', 'criticism', 'liquidation politics', 'exchanges of shots', 'explosions'. Details of the event are further visualized in linguistic snapshots produced by nouns combined with verbs, cf.: 'tracers cut across the night sky'. An overall picture of the event is formed by means of words that, with the synecdoche, describe selected parts of the whole on a recognizable, basic level. Hypothesis $\mathrm{H} 2$ is thus supported by these observations.

\section{$\operatorname{Re} 2$.}

Personal characteristics: The writer of the article mixes different metaphorical meanings: The person Trine Gregorius (= the target domain of the metaphor) is characterized in the text by way of meanings from a source domain. They present her as a hybrid between a Rottweiler and a sour schoolmistress who is capable of 'cracking the whip'. This image is of course fiction, but it contains the construction of a female TV show host who is able to bite as well as beat. In this way, fiction may add meaning to factual media news. Internal correspondences between the source and target domain of the metaphor are, however, an important precondition. These correspondences exist in the historical context of the article where Trine Gregorius, as a columnist, has already shown some of the aggressive qualities that the source domain depicts and further amplifies. In other words, she has demonstrated qualities that show that she is appropriate for the role. We call this type of exposure through complex metaphors blended exposure or just blending. These observations support Hypothesis H2.

\section{Re 3.}

Political power struggle: The writer uses metaphors to make clear the attitudes in a conflict between two parties. The one side (the 'green' organizations) is presented as explaining 'nature' as a delicate and vulnerable organism that needs protection. The other side (the representatives of the agricultural industry) is presented as describing the same 'nature' as a sturdy machine capable of handling a great deal more than what the counterpart imagines. To begin with, the first part ('nature') of the dual conception 'nature protection' is synedochally connected with expressions such as 'Danish bogs', 'commons', 'heaths' and 'natural forests'. The other part in the conception ('protection') is synecdochally connected with the positively charged words 'encircled', 'security area', and 'buffers'. These individual linguistic parts present the content of the nature conception in which the green organizations start off during the political confrontation. In these observations, support is found for Hypothesis H2.

\section{Re 4.a}

Scandal: Thin stories may achieve more substance if the narrator expresses his/her attitudes, in this case indignation. The presentation is not based on observations or opinions from sources, but on (the journalist's own) opinions and attitudes, which are not further documented. "African frauds have ... fallen upon Folketinget (The Danish Parliament)", the article states in its subheading. The story is about spam-mail sent to 
members of Folketinget. "With promises of inconceivable wealth" the frauds have "stolen fortunes from Danish businessmen" it is stated in the text. The narrator's assessments are the reader's only basis for understanding the motives and actions of the story. The narrator uses synecdoche as a tool. But the resulting description is not supported by quoted statements from sources. And the reader will look in vain for documentation of the truth-value and content of the attitude exposures. Even if the observations confirm Hypothesis H2, it may be an instance of exaggeration and pure fiction. In this way, it is a confirmation of Hypothesis $\mathrm{H} 3$.

\section{$\operatorname{Re} 4 . b$}

Sympathy: In the last example, the narrator's indignation is found side by side with sympathy. The article is about a 13-year-old girl who is going to give evidence in a rape trial where she herself has been a victim. The sympathy with the victim's situation appears already in the heading "Forced to relive sex nightmare" and in the summary of the article: "For hours a frightened school girl had to explain about her shocking rape experience in the court in Odense". This attitude towards the victim is followed up in the body of the article by a detailed person description. It is based on observations of concrete features that have been selected with the purpose of arousing sympathy with a sympathetic ('the dark, sleek hair to the shoulder) and frightened ('pale and with startled eyes') victim. The basic mechanism in the description of the article is the synecdoche: The narrator uses attitude exposures, but combines them with exposures of the actors and part of the story's course of events, which is based on observations and source statements. In this way, the writing method seems to support Hypotheses H2 and H3.

\section{Summary and Perspectives}

The qualitative analysis shows that events, event-related acts, objects, scenes, persons and personal attitudes (Hypothesis $\mathrm{H} 2$ ) are brought into focus, intensified and elaborated by means of exposure. Using exposures in the news texts appears as results of narrator activity. By acting as narrator instead of informant of news based on sources, the writer's reliability is at stake (Hypothesis H3). Table 1 (p. 101) shows that not all of the examined media are inclined to run this risk.

Some of them (Berlingske Tidende, Morgenavisen Jyllands-Posten and partly B.T.) stick to the informant norm, which contains a well-established model for news coverage. This means that the narrative code in these newspapers offers more restrained language and the news articles in question resemble each other.

To demonstrate the linguistic consequences in detail and to test Hypothesis H1 (cf. p. 103), the number of cases are increased from the 50 units to maximum. In this material, two versions of the same piece of news are found. The versions are front-page articles that occupy the upper third of a broadsheet page. The articles are from Berlingske Tidende and Politiken. They tell the same story, but with different frames, different sources and different narrative codes as well. By comparing these versions, it was furthermore possible to test the sensitivity of the statistical model used on the data. The first article informs about its story and the second narrates it by means of different exposures: 


\title{
Parents Satisfied with School
}

\section{Berlingske Tidende, 6 August 2001, SECTION 1, page 1}

Mark book: A Gallup poll shows that eight in ten parents are satisfied with primary and lower secondary school (Folkeskolen). "A clearer distribution of responsibility between teachers and parents can make Folkeskolen even better," minister declares.

\section{By Henrik Dannemand}

The majority of the parents of the just under 70,000 children, who start school today and within the next few days, can safely look forward to their children's new school life with anticipation.

Indeed, a new Gallup poll shows that there is general satisfaction with Folkeskolen among parents who already have children in school.

Eight in ten parents are satisfied with the teaching. The poll, which is based on interviews with a representative sample of the population, shows that only 12 per cent are dissatisfied.

"I think that the parents are satisfied with two things. They sense that their children are learning. They come home and tell that they experience things in school and the parents notice that the children want to, e.g., read signs in the supermarket. The other thing is that Folkeskolen offers the possibility of developing other qualities than academic skills", says Minister of Education Margrethe Vestager (R).

She also says that it is difficult for her to be dissatisfied with the results of the poll, but she focuses on the fact that two in ten parents declare that they are dissatisfied. If Folkeskolen is to improve, we need clearer objectives for teaching and a more distinct distribution of responsibility between teachers and parents. [Abbreviated]

\section{More Pupils in the Classrooms}

\author{
Politiken, 6 August 2001, 1. section page 1
}

60,000 children will begin in Folkeskolen within the next few days. The little school starters have to sit closer for there will be more pupils in the new classes. Teachers and parents feel uneasy.

\section{By Hanne Fall Nielsen, Mona Samir Sфrensen and Tanja Parker Astrup}

The next days' newcomers in the Danish Folkeskole will have to sit close, and more children in each of the junior classes means increased competition for the teacher's attention.

These are among the conclusions of a poll conducted among the largest municipalities in the country. On average they put an additional one or two more pupils into the junior classes and this means that many classes will hit the limit of 28 pupils. A similar tendency can be found in the rest of the country, says chairman of the school committee of Kommunernes Landsforening (KL) (The National Association of Local Authorities in Denmark), Else Købstrup (V) (The Liberal Party): 
"In places, where the number of children increases - this happens in the majority of the municipalities - the schools try to solve the problem without making more classes if possible. In the municipalities, there has never been more focus on getting the best possible value for money than just now", she declares.

The average price per pupil is evidence that more children are taught in each classroom. The more pupils in a class, the lower the price per pupil.

It is expected that the average price per pupil will drop by between DKK 500 to 1,000 in the coming school year, says director Niels Bertelsen from KL. From 2000 to 2001 the average price per pupil fell from 42,319 to 39,298 DKK.

[Abbreviated]

The narrator's visible presence in the first article from Berlingske Tidende is limited to the assessing adverb 'safely' in paragraph 1 . The security inherent in the positive assessment is supported by the adverb 'indeed' in paragraph 2, but apart from that, Berlingske Tidende's writer keeps a low linguistic profile as a narrator. The discrete indications tell something about Berlingske Tidende's frame, which is quite positive, whereas Politiken's is negative and critical. In Politiken the narrator is also more active through exposures. These observations confirm that Politiken is a narrator-active newspaper (cf. Table 1, p. 101). Politiken's narrator constructs a descriptive future scenario, which is hypothetical in the sense that it is about what will probably happen not about what has happened.

Thus, the writing method of Politiken deviates markedly from that of Berlingske Tidende. This is also supported by the statistical estimates in Figure 1 (p. 99). Politiken's narrator takes responsibility and runs a risk in the opening construction ('The little school starters', 'newcomers', 'will have to sit close', 'increased competition for the teacher's attention') and subsequently does not refer to any source. Later 'the average price' is mentioned, where a commodity terminology (slightly ironically) functions as source domain and contributes to the commercial perspective at the target domain 'school children'. Once more a construction is found, which shows the narrator's explicit presence as the agenda-defining authority in language and communication.

So, two news articles are present that communicate the same story, but use different approaches. A linguistic analysis indicates low and high narrator activity, respectively. If the linguistic analysis of this case is compared with the logistic regression analysis of the data, it seems there is good reason - with reference to the method - to be satisfied with the fact that the Berlingske Tidende article was ranked number 1,217 in the statistical order, which is shown by the first 50 numbers in Table 2 (p. 102). In comparison, the Politiken article has observation number 207, indicating an increased average probability that the writer chooses a narrator role that enables exposures to occur. Thus, Hypothesis H1 seems to be confirmed. The results would seem to indicate that the quantitative and the qualitative approach to analysis of the material are in perfect accordance in this case.

\section{Conclusions}

Exposures are described as linguistic types of constructions that presuppose the use of an active journalistic narrator. The means of creating exposures is figurative language based on structures of a conceptual character. Exposures are not only found in the narrative-inclined genres of journalism such as feature, coverage and profile. The analy- 
sis demonstrates that news journalism with varying frequency uses these characteristics in the investigated newspapers.

An explanation as to why journalists would use exposures is based on the supposition that exposures increase recognition and comprehensibility and thus contribute to the ease of reading and understanding a newspaper. It is also assumed that exposures have found their way into news journalism because the financial conditions of newspaper production have become increasingly more difficult, partly as a consequence of the newspapers' fierce competition with the electronic media.

The analysis shows which media in particular (Politiken and Ekstra Bladet) make use of exposures and, by way of qualitative analyses of selected texts, some of the major exposure techniques are found. In news journalism, metonymy and synecdoche occur in the descriptive paragraphs together with visual idioms. Some of the techniques found function as elements of complex metaphors, which form a new meaning by transferring analogue structures between different, but interconnected conceptual domains.

It is suggested that other exposure techniques may be considered, e.g. hypothetic or counterfactual descriptions and reconstructions of events that have already taken place. These are rarer in news journalism, but cannot be ruled out altogether.

It remains to be examined within which type of content matter exposures most frequently occur. Sports journalism is an area filled to the brim with perceptive idiomatic expressions that establish a high degree of familiarity or recognition. The same seems to be true of other journalistic special areas, e.g. business and cultural journalism.

Finally, an approach is demonstrated in which quantitative and qualitative methods can be combined to supplement each other in order to show the details of the journalistic method of creating comprehension. The method can be developed to make it possible to follow and, in a relatively short time, describe the development patterns in the newspapers' daily text production, which today is subjected to rapid transformation.

\section{Notes}

1. Cf. Table 2.3 on the daily papers' media activities 2003 (Statsministeriet 2004, p. 37). Apart from general commercial newspaper production media activities comprise: Internet papers, free weekly papers, traffic papers, radio, television, mobile services, books and magazines.

2. The latest controlled figures from the independent Oplagskontrol/Oplagskontrol (2005) confirm that the negative development continues: cp. figures for dailies, first half year: Politiken: 142,012 (2002), 137,479 (2003), 134,391 (2004). Jyllands-Posten: 179,716 (2002), 172,489 (2003), 157,701 (2004). Berlingske Tidende: 148,853 (2002), 142,483 (2003), 130,487 (2004). B.T.: 120,796 (2002), 110,148 (2003), 100,537 (2004). Ekstra Bladet: 119,331 (2002), 110,379 (2003), 105,839 (2004).

3. See the example in Grunwald, E., G. Smistrup et al. (1992) p. 120.

4. The concept communication act has been developed from the theory of speech acts. Cf. a more detailed argumentation in Grunwald (2003), p. $71 \mathrm{ff}$.

\section{References}

Fauconnier, G. and M. Turner (2002) The Way We Think: Conceptual Blending and the Mind's Hidden Complexities. New York: Basic Books.

Garrison, Bruce and Michel Dupagne (2003) A Case Study of Media Convergence At Media General's Tampa News Center. Expanding Convergence: Media Use in a Changing Information Environment, University of South Carolina, Columbia, SC, November 6-8, 2003.

Gibbs, R.W. (1993) 'Process and Products in Making Sense of Tropes, in A. Ortony (ed.), Metaphor and Thought. Cambridge, New York, Melbourne: Cambridge University Press, pp. 252-276.

Grunwald, E.,G. Smistrup et al. (1992) Journalistens sprog. Med et sprogligt serviceeftersyn. [The language of the journalist - with a linguistic check-up]. Århus: Ajour. 
Grunwald, E. (2003). 'Avisnyheders narrative fundament'. [The narrative base of printed news]. Nordicom Information 2003(3), pp. 69-82.

Oplagskontrol, D. (2005). Kontrollerede oplagstal. [Controlled circulation figures.] [http://www.do.dk] København: Dansk Oplagskontrol.

Petersen, Anja Bechmann (2006) 'Medielandskabets voksende flermedialitet, tvaermedialitet og nye mediekoncepter?' [The Growth of Multiple Platforms, Cross-mediality and New Concepts of the Media?]. Samson 16(3): 15-17.

Statsministeriet (2004). Betankning nr. 1445. Arbejdsgruppen om Dagspressens Finansieringsinstitut. [Report number 1445. The Working Group about the Financial Dept. of the Press] København: Statsministeriet.

EBBE GRUNWALD, Mag.Art., Associate Professor; Center of Journalism, Department of Language and Communication, University of Southern Denmark, Campusvej 55, DK5230 Odense M, ebg@journalism.sdu.dk

JØRGEN LAURIDSEN, Ph.D., Associate Professor; Department of Economics, University of Southern Denmark, Campusvej 55, DK-5230 Odense, jtl@sam.sdu.dk 